Semblanza de Hugo Guerrero Marthineitz

Amelia Troisi

Question/Cuestión, Vol. 2, № 66, Agosto 2020

ISSN 1669-6581

https://perio.unlp.edu.ar/ojs/index.php/question/index

IICom-FPyCS-UNLP

\title{
UNA SEMBLANZA DE HUGO GUERRERO MARTHINEITZ
}

\section{A STORIE ABOUT HUGO GUERRERO MARTHINEITZ}

\begin{abstract}
Amelia Troisi
Locutora y Periodista

Coordinadora General a cargo del Rotativo del Aire de Radio Rivadavia
\end{abstract}

\section{Resumen}

Amelia Troisi describe la trayectoria de Hugo Guerrero Marthineitz, locutor y conductor de radio y televisión peruano, reconocido como uno de los más innovadores en el medio radial.

\section{Palabras clave}

Radio de autor, Locutor, Comunicador 


\section{Abstract}

Amelia Troisi describes the career of Hugo Guerrero Marthineitz, Peruvian radio and television announcer and host, recognized as one of the most innovative in the radio medium.

\section{Keywords}

Author's radio, Announcer, Communicator

\section{Enlace}

https://go.ivoox.com/rf/55625426 